\title{
Interfacial Impedance of Austenitic Stainless Steel under Anodic Polarization
}

\author{
Katsuhisa Sugimoto and Yoshinobu Sawada \\ Department of Metallurgy, Faculty of Engineering, Tohoku University*
}

\begin{abstract}
Variations in the interfacial impedance of the electrode of AISI Type 304 stainless steel in electrolytic solutions of sodium sulphate have been measured as a function of polarizing voltage under anodic polarization. The capacitive component of the impedance exhibits three characteristic changes with potential and these changes correspond to the transitions from the passive to the transpassive state, from the transpassive to the secondary passive state and from the secondary passive to the oxygen evolution state which are observed in the current-potential curve of this steel. However, the changes observed in the capacitance-potential curve always appear at more negative potentials than the potentials at which the corresponding changes are observed in the polarization curve. These phenomena are discussed on the basis of compositional changes in the passive film.
\end{abstract}

\section{Introduction}

The interfacial impedance of austenitic stainless steel electrodes in aqueous solutions of sodium sulphate has been investigated over a region of the corrosion potential to the oxygen evolution potential in order to clarify changes in properties of surface films formed during anodic polarization. The typical example of the variations in capacitance, resistance and anodic current with potential for a commercial AISI Type 304 stainless steel in a neutral solution of $1 \mathrm{M}-\mathrm{Na}_{2} \mathrm{SO}_{4}$ is shown in Fig. 1. Two minimums and one maximum of capacitance are usually observed in the capacitive component-potential curve ( $C-E$ curve), which are herein designated $C_{1}, C_{2}$, and $C_{3}$, respectively. One maximum of resistance is also observed in the resistive component-potential curve $(R-E$ curve), which is designated $R_{1}$. A similar behavior of the $C-E$ and $R-E$ curves for Type 304 stainless steel measured by an A.C. bridge method has been observed by Pražák, ${ }^{1)}$ Morioka, ${ }^{2)}$ Okamoto, ${ }^{3)}$ and the present authors. ${ }^{4}$

However, there arises a question as to whether the changes in the $C-E$ curve correspond to those in the anodic polarization curve measured at the same time with the $C-E$ curve because the potentials of $C_{1}, C_{2}$ and $C_{3}$ in the $C-E$ curve are more negative by $150-200 \mathrm{mV}$ than the transition potentials from passivity to transpassivity, transpassivity to secondary passivity and secondary passivity to oxygen evolution in the anodic

* Aza-Aoba, Aramaki, Sendai-shi, 980, Japan polarization curve, respectively. The present study was carried out so as to determine the electrode reactions by which the changes of $C_{1}, C_{2}$ and $C_{3}$ in the $C-E$ curve and $R_{1}$ in the $R-E$ curve are caused.

To make clear the influence of alloying elements on the electrode impedance for Type 304 stainless steel, the $C-E$ and $R-E$ curves of Type 304 stainless steel were compared with those for pure iron, pure chromium, pure nickel, binary $\mathrm{Fe}-\mathrm{Cr}$ alloys and a binary $\mathrm{Fe}-\mathrm{Ni}$ alloy. Further, to investigate the correspondence between the changes in electrode impedance and electrode reactions, the dependence of the potentials for $C_{1}, C_{2}, C_{3}$ and $R_{1}$ on the $\mathrm{pH}$ of solutions was compared with those of the transition potentials in the anodic polarization curves.

\section{Experimental Procedure}

Experimental arrangement composed of a potentiostat and an A.C. bridge was used for measurements of the electrode impedance during potentiostatic polarization. ${ }^{5,6)}$ Balance points of the bridge were detected by using a synchroscope with an amplitude of vertical axis up to $5 \mathrm{mV} / \mathrm{cm}$. If necessary, a differential amplifier with a gain of $60 \mathrm{~dB}$ was used to increase the amplification of the synchroscope. The frequency of the applied A.C. wave was $1000 \mathrm{~Hz}$ and its amplitude was less than $7 \mathrm{mV}$. A specimen and an auxiliary platinum electrode for the D.C. supply were placed separately in two compartments of an H-type cell made of Pyrex glass and a platinized 


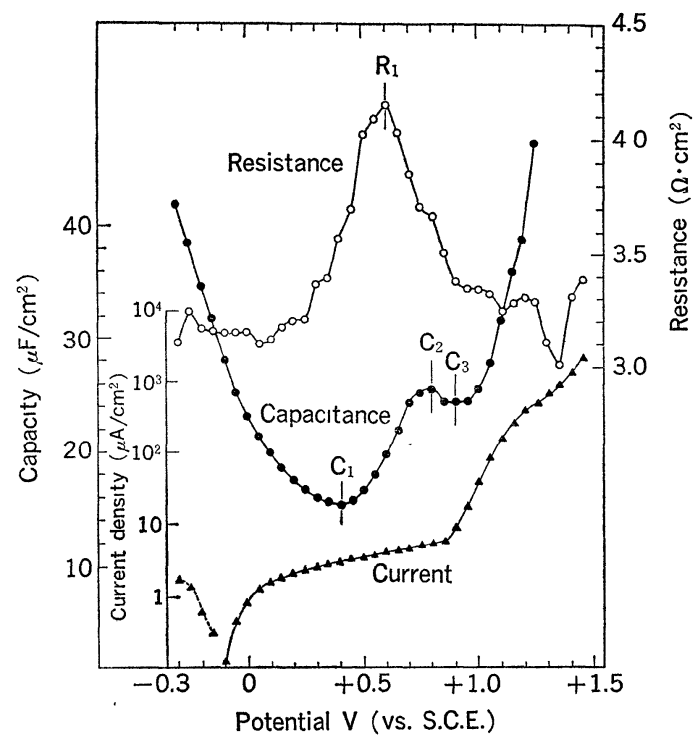

Fig. 1. The typical example of the variations in capacitance, resistance and anodic current with potential for Type 304 stainless steel in $1 \mathrm{M}-\mathrm{Na}_{2} \mathrm{SO}_{4}$ solution at $\mathrm{pH} 6.4$.

platinum electrode for the impedance measurement was set in one of the compartments at a distance of $2 \mathrm{~cm}$ from the specimen.

Electrode impedances and anodic currents were measured at the same time at given potentials. Both measurements were made after holding electrode potential for $5 \mathrm{~min}$ at each setting potential which was obtained by changing potentials from the corrosion potential toward the positive direction at intervals of $50 \mathrm{mV}$. The bridge was balanced by using an equivalent $\mathrm{RC}$ network having a series combination of a capacitor and a resistor. A saturated calomel electrode was used for the reference in potential measurements.

A commercial AISI Type 304 stainless steel was used as specimens. Effects of alloying elements, such as $\mathrm{Fe}, \mathrm{Cr}$, and $\mathrm{Ni}$, on the impedance were also examined by using pure iron, pure chromium, pure nickel, binary $\mathrm{Fe}-\mathrm{Cr}$ alloys $(20-70 \% \mathrm{Cr})$ and a binary $\mathrm{Fe}-40 \% \mathrm{Ni}$ alloy. The chemical compositions and the heat treatment conditions of the specimens are listed in Table 1. Specimen surfaces were prepared by finishing with cloth after polishing with emery papers up to No. 6/0. The rest of the specimen surface except the exposed area of $1 \mathrm{~cm}^{2}$ was covered with a resin insulator.

In most cases, a neutral solution of $1 \mathrm{M}-\mathrm{Na}_{2} \mathrm{SO}_{4}$ at $\mathrm{pH} 6.4$ was used as the electrolyte. When

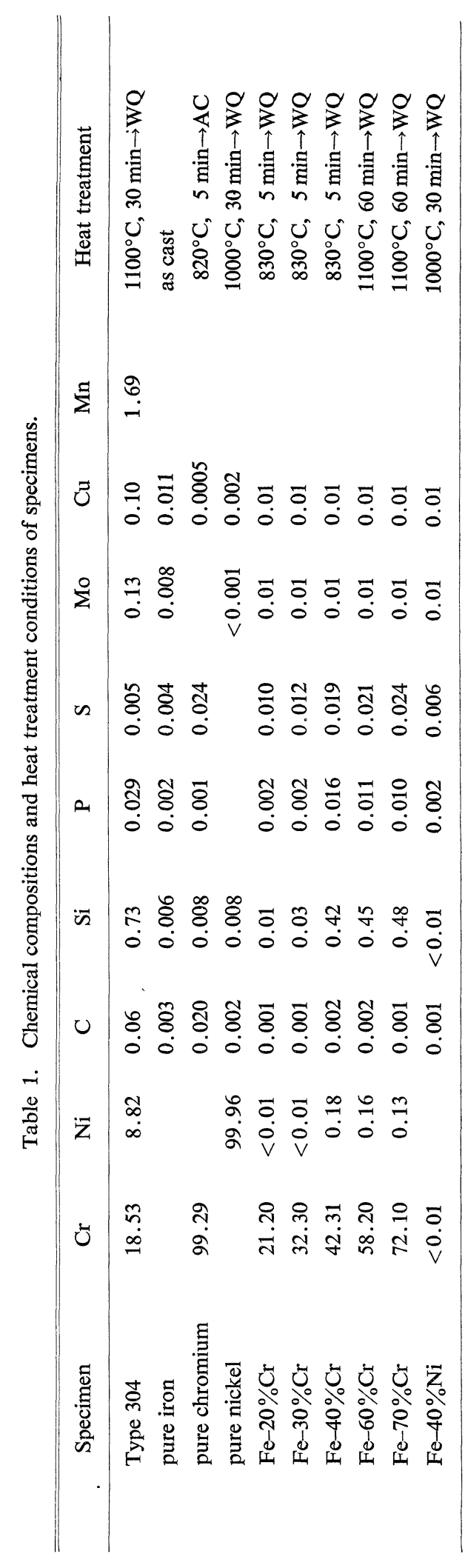


necessary, the $\mathrm{pH}$ of the solutions was adjusted in the range of 0 to 8.0 by adding a small amount of $\mathrm{H}_{2} \mathrm{SO}_{4}$ or $\mathrm{NaOH}$ solution keeping the concentration of $\mathrm{SO}_{4}^{2-}$ ion in the solutions constant $(1 \mathrm{~g}$-ion $/ L)$. The electrolytes were prepared from reagent-grade chemicals and distilled water with the specific conductivity of $2 \times 10^{-6} \Omega^{-1} \mathrm{~cm}^{-1}$. Purified nitrogen gas was bubbled through the cell for more than 20 min before measurements. Measurements were made in a nitrogen atmosphere at a temperature of $25 \pm 0.5^{\circ} \mathrm{C}$ under the condition of a stationary state.

\section{Experimental Results}

\subsection{Relations between alloy compositions and variations in the $\boldsymbol{C}-\boldsymbol{E}$ and $\boldsymbol{R}-\boldsymbol{E}$ curves}

\subsubsection{Iron}

The $C-E$ curve, the $R-E$ curve and the anodic polarization curve for pure iron measured in $1 \mathrm{M}-\mathrm{Na}_{2} \mathrm{SO}_{4}$ solution (pH 6.4) are shown in Fig. 2. The shape of the $C-E$ curve for pure iron is quite different from that for Type 304 stainless steel; that is, neither maximum nor minimum of capacitance corresponding to $C_{1}$ and $C_{2}$ for Type 304 stainless steel appears in the $C-E$ curve for pure iron, and the values of capacitance in the potential range of +0.30 to $+1.15 \mathrm{~V}$ corresponding to the passivity of iron decrease with increasing in potential.

\subsubsection{Chromium}

The anodic polarization curves for pure chromium and binary $\mathrm{Fe}-\mathrm{Cr}$ alloys measured in

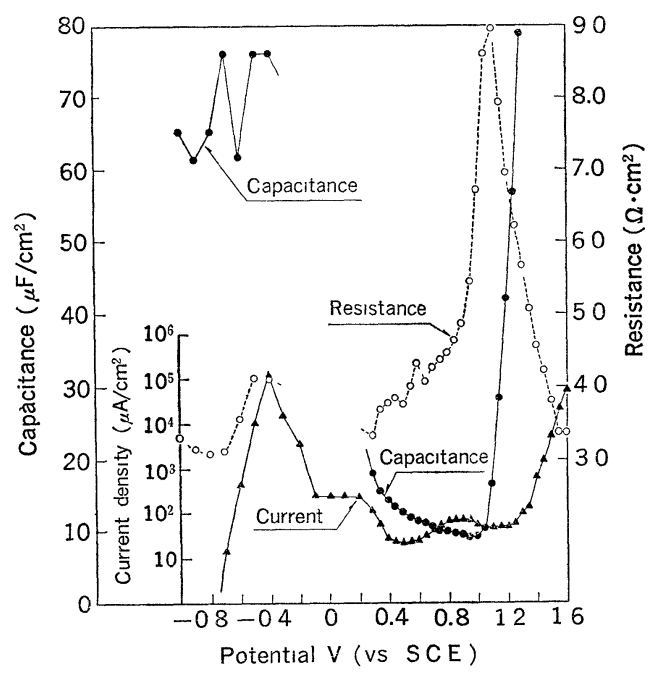

Fig. 2. Variations in capacitance, resistance and anodic current with potential for pure iron in $1 \mathrm{M}-\mathrm{Na}_{2} \mathrm{SO}_{4}$ solution at $\mathrm{pH} 6.4$.
$1 \mathrm{~m}-\mathrm{Na}_{2} \mathrm{SO}_{4}$ solution (pH 6.4) are shown in Fig. 3. The $C-E$ and $R-E$ curves for them are also shown in Figs. 4 and 5, respectively.

The $C-E$ curves for pure chromium and binary $\mathrm{Fe}-\mathrm{Cr}$ alloys containing 60 and $70 \%$ chromium which exhibit transpassivity but no secondary passivation in the anodic polarization curves show only one minimum of capacitance corresponding to $C_{1}$ at $+0.30 \mathrm{~V}$, while those of binary $\mathrm{Fe}-\mathrm{Cr}$ alloys containing 20 to $40 \%$ chromium have two maximums at -0.30 and $+0.70 \mathrm{~V}$, which are designated $C_{(\mathrm{Fe}-\mathrm{Cr}) 0}$ and $C_{(\mathrm{Fe}-\mathrm{Cr}) 2}$,

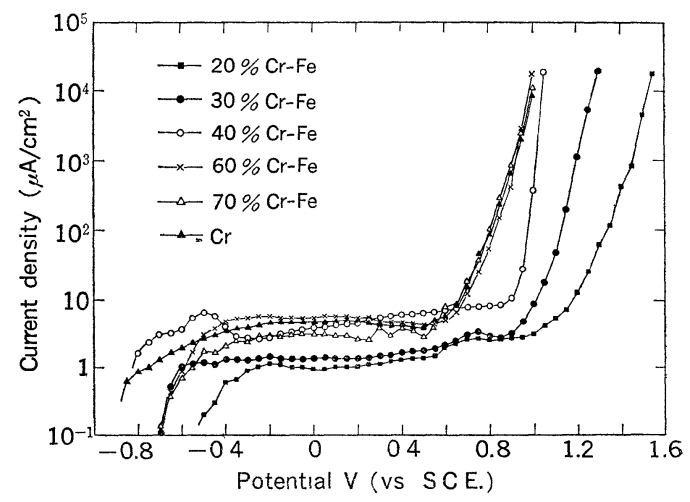

Fig. 3. Anodic polarization curves for pure chromium and binary $\mathrm{Fe}-\mathrm{Cr}$ alloys in $1 \mathrm{M}$ $\mathrm{Na}_{2} \mathrm{SO}_{4}$ solution at $\mathrm{pH} 6.4$.

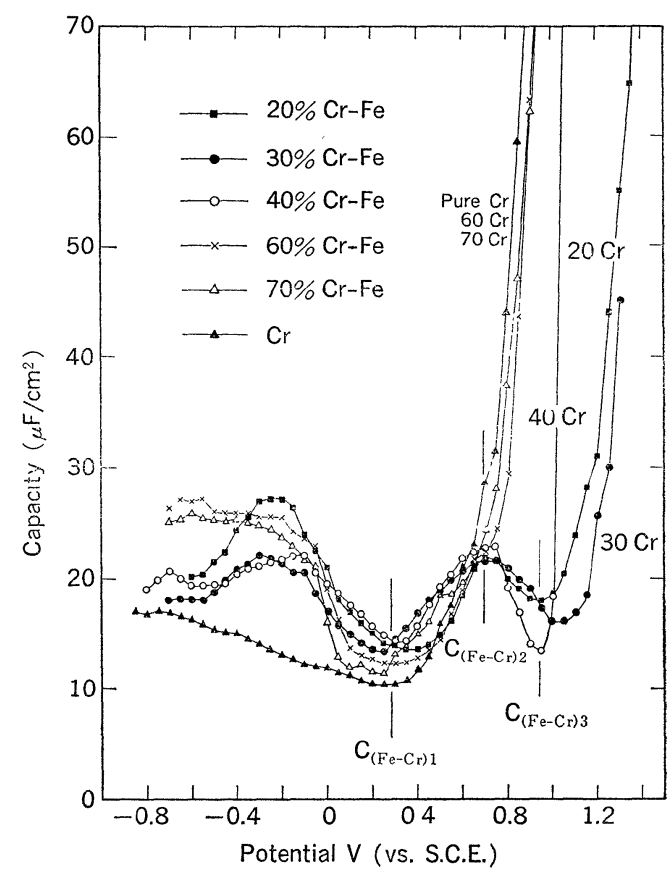

Fig. 4. Variations in capacitance with potential for pure chromium and binary $\mathrm{Fe}-\mathrm{Cr}$ alloys in $1 \mathrm{M}-\mathrm{Na}_{2} \mathrm{SO}_{4}$ solution at $\mathrm{pH} 6.4$. 
respectively, and two minimums at +0.35 and $+0.95 \mathrm{~V}$, which are designated $C_{(\mathrm{Fe}-\mathrm{Cr}) 1}$ and $C_{(\mathrm{Fe}-\mathrm{Cr}) 3}$, respectively.

The relations between the potentials of $C_{(\mathrm{Fe}-\mathrm{Cr}) 1}$, $C_{(\mathrm{Fe}-\mathrm{Cr}) 2}$ and $C_{(\mathrm{Fe}-\mathrm{Cr}) 3}$ in the $C-E$ curves and the chromium content for $\mathrm{Fe}-\mathrm{Cr}$ alloys are shown in Fig. 6. The potential of $C_{(\mathrm{Fe}-\mathrm{Cr}) 1}$ depends on the chromium content of the binary alloys and shifts in negative direction with an increase in chromium content, while the potentials of $C_{(\mathrm{Fe}-\mathrm{Cr}) 2}$ and $C_{(\mathrm{Fe}-\mathrm{Cr}) 3}$ are independent of the chromium content. Not only the potentials but also the capacitance values of $\mathrm{C}_{(\mathrm{Fe}-\mathrm{Cr}) 1}, C_{(\mathrm{Fe}-\mathrm{Cr}) 2}$ and $C_{(\mathrm{Fe}-\mathrm{Cr}) 3}$ for $\mathrm{Fe}-\mathrm{Cr}$ alloy containing chromium about $18 \%$ agree quite well with those of

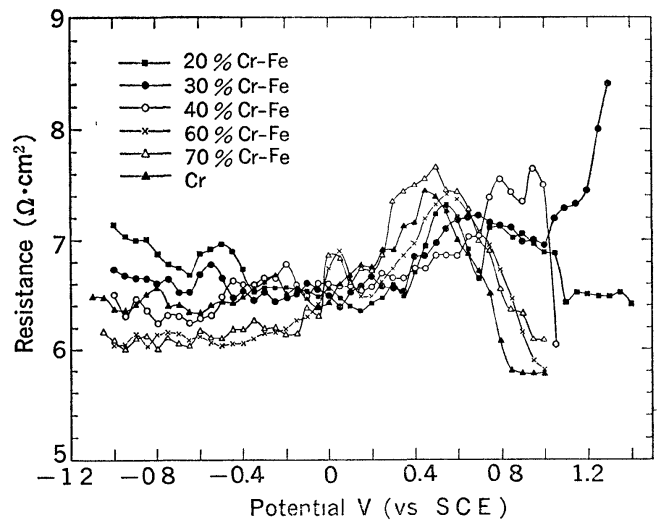

Fig. 5. Variations in resistance with potential for pure chromium and binary $\mathrm{Fe}-\mathrm{Cr}$ alloys in $1 \mathrm{M}-\mathrm{Na}_{2} \mathrm{SO}_{4}$ solution at $\mathrm{pH} 6.4$.

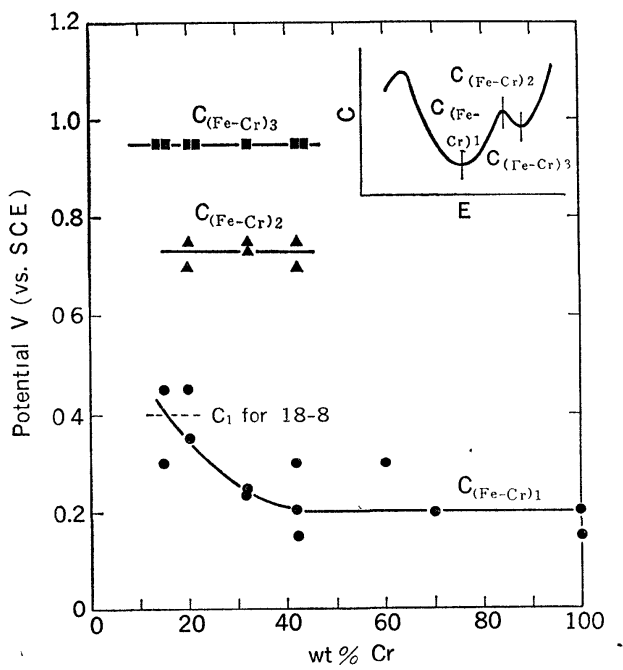

Fig. 6. Relations between the potentials of $C_{(\mathrm{Fe}-\mathrm{Cr}) 1}, C_{(\mathrm{Fe}-\mathrm{Cr}) 2}$ and $C_{(\mathrm{Fe}-\mathrm{Cr}) 3}$ in the $C-E$ curves and the chromium content of $\mathrm{Fe}-\mathrm{Cr}$ alloys.
$C_{1}, C_{2}$ and $C_{3}$ for Type 304 stainless steel (see Fig. 1).

The maximum of resistance is observed at about $+0.50 \mathrm{~V}$ in the $R-E$ curves for pure chromium and binary $\mathrm{Fe}-\mathrm{Cr}$ alloys containing chromium up to $70 \%$, which is designated $R_{(\mathrm{Fe}-\mathrm{Cr}) 1}$. The potential of $R_{(\mathrm{Fe}-\mathrm{Cr}) 1}$ is also almost equal to that of $R_{1}$ for Type 304 stainless steel.

\subsubsection{Nickel}

The $C-E, R-E$ and anodic polarization curves for pure nickel and a binary $\mathrm{Fe}-40 \% \mathrm{Ni}$ alloy measured simultaneously in $1 \mathrm{M}-\mathrm{Na}_{2} \mathrm{SO}_{4}$ solution (pH 6.4) are shown in Fig. 7. The $C-E$ curve of $\mathrm{Fe}-40 \% \mathrm{Ni}$ alloy has one maximum at $-0.20 \mathrm{~V}$ in the potential region of active dissolution and one minimum near a middle potential of the passivity region, $+0.45 \mathrm{~V}$, which are designated $C_{(\mathrm{Fe}-\mathrm{Ni}) 0}$ and $C_{(\mathrm{Fe}-\mathrm{Ni}) 1}$, respectively. The potential and capacitance of $C_{(\mathrm{Fe}-\mathrm{Ni}) 1}$ are nearly equal to those of $C_{1}$ for Type 304 stainless steel. Pure nickel exhibits the transpassivity, secondary passivation and oxygen evolution in the anodic polarization curve. The $C-E$ curve for pure nickel has two maximums (at -0.20 and $+0.75 \mathrm{~V}$ ) and three minimums (at $-0.4,0.0$ and $+1.05 \mathrm{~V}$ ). The shape of the $C-E$ curve between about $-0.20 \mathrm{~V}$

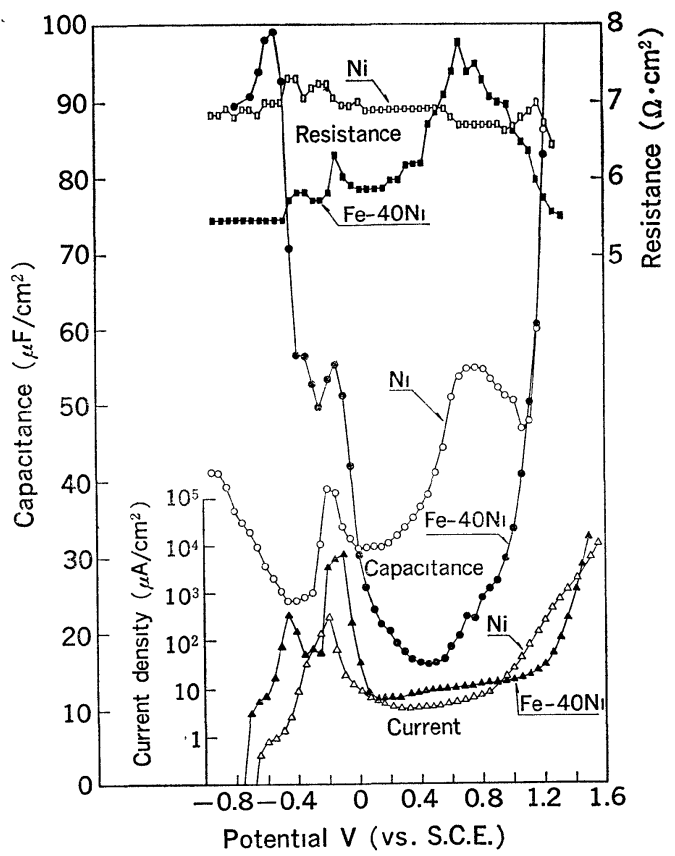

Fig. 7. Variations in capacitance, resistance and anodic current with potential for pure nickel and $\mathrm{Fe}-40 \% \mathrm{Ni}$ alloy in $1 \mathrm{M}-\mathrm{Na}_{2} \mathrm{SO}_{4}$ solution at $\mathrm{pH} 6.4$. 
and $+1.20 \mathrm{~V}$ bears close resemblance to that for Type 304 stainless steel. However, the potentials and capacitances for the minimums and the maximums are different from those for Type 304 stainless steel.

The $R-E$ curve for $\mathrm{Fe}-40 \% \mathrm{Ni}$ alloy shows only one maximum at $+0.65 \mathrm{~V}$, which is designated $R_{(\mathrm{Fe}-\mathrm{Ni}) 1}$. The potential of $R_{(\mathrm{Fe}-\mathrm{Ni}) 1}$ is nearly equal to that of $R_{1}$ for Type 304 stainless steel.

\subsection{Effects of the $\mathrm{pH}$ of solutions on the $C-E$ and $\boldsymbol{R}-\boldsymbol{E}$ curves}

Variations of the $C-E$ and $R-E$ curves for Type 304 stainless steel with the pH of $1 \mathrm{M}-\mathrm{Na}_{2} \mathrm{SO}_{4}$ solutions are shown in Figs. 8 and 9, respectively. Variations of the anodic polarization curves with the $\mathrm{pH}$ of the solutions are also shown in Fig. 10. With a decrease in $\mathrm{pH}$ of the solutions, the variations in current corresponding to the active dissolution, passivity, transpassivity, secondary passivation and oxygen evolution are clearly distinguishable in the anodic polarization curves.

The relations between the $\mathrm{pH}$ of solutions and transition potentials in the anodic polarization curves in Fig. 10 are shown in Fig. 11. Linear relations are obtained for the potentials $E_{1}, E_{2}$

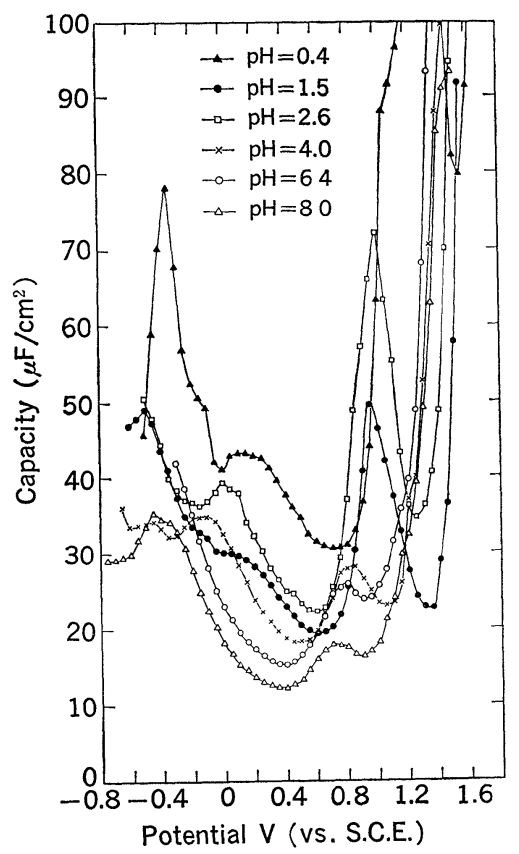

Fig. 8. Variations in the $C-E$ curves for Type 304 stainless steel with the $\mathrm{pH}$ of $1 \mathrm{M}-\mathrm{Na}_{2} \mathrm{SO}_{4}$ solutions. and $E_{3}$, which are the transition potentials from the passive to the transpassive state, the transpassive to the secondary passive state, and the secondary passive to the oxygen evolution state, respectively.

$$
\begin{array}{ll}
E_{1}: & E=0.900-0.063 \mathrm{pH}, \\
E_{2}: & E=1.313-0.137 \mathrm{pH}, \\
E_{3}: & E=1.647-0.103 \mathrm{pH} .
\end{array}
$$

The capacitances and potentials of $C_{1}, C_{2}$ and

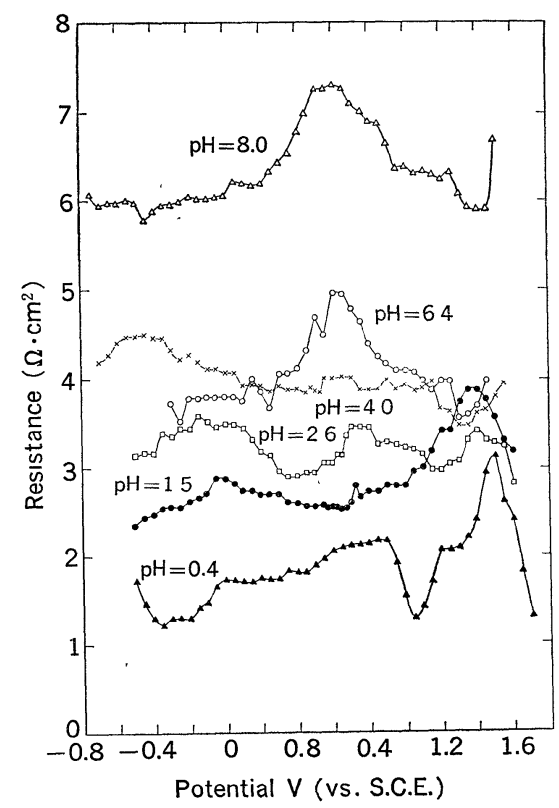

Fig. 9. Variations in the $R-E$ curves for Type 304 stainless steel with the $\mathrm{pH}$ of $1 \mathrm{M}-\mathrm{Na}_{2} \mathrm{SO}_{4}$ solutions.

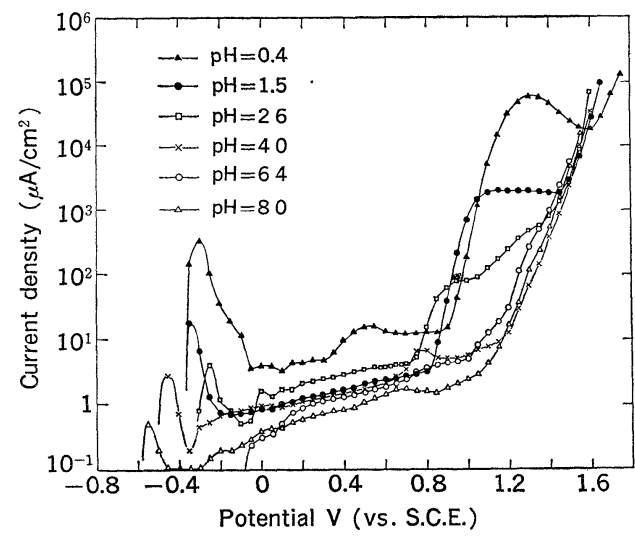

Fig. 10. Variations of the anodic polarization curves with the $\mathrm{pH}$ of $1 \mathrm{M}-\mathrm{Na}_{2} \mathrm{SO}_{4}$ solutions. 
$C_{3}$ depend on the $\mathrm{pH}$ of solutions; that is, the potentials of $C_{1}, C_{2}$ and $C_{3}$ shift in positive direc-

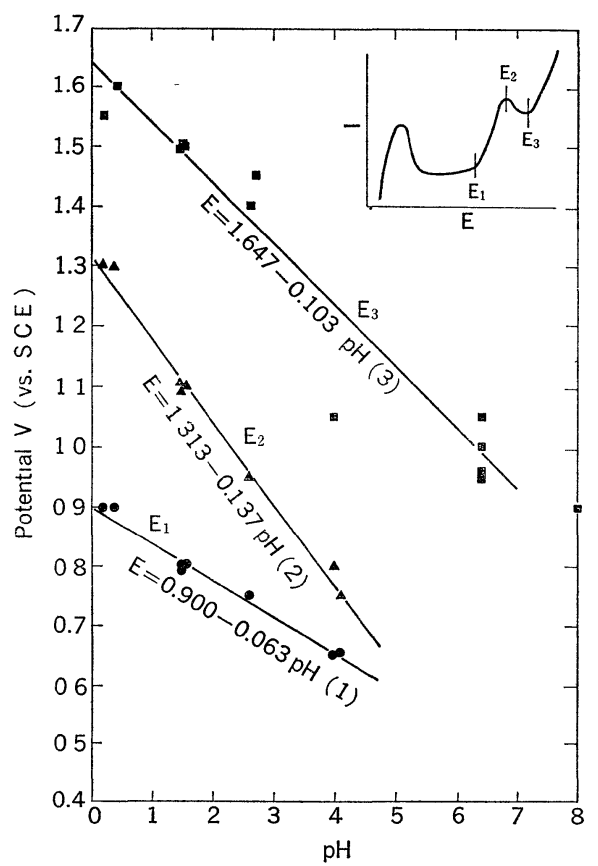

Fig. 11. Relations between the pH of solutions and transition potentials in the anodic polarization curves for Type 304 stainless steel.

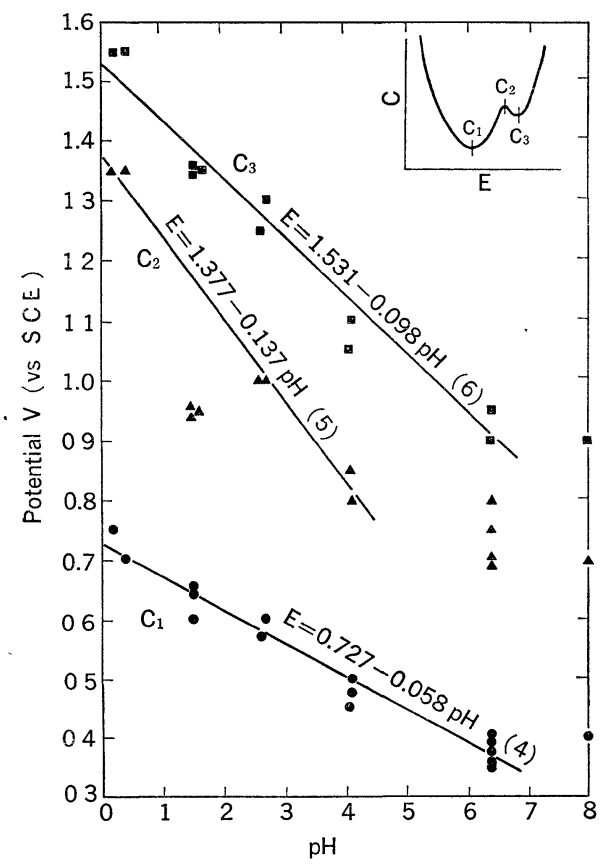

Fig. 12. Relations between the $\mathrm{pH}$ of solutions and the potentials of $C_{1}, C_{2}$ and $C_{3}$ for Type 304 stainless steel. tion and the variations in capacitance with potential become pronounced as the $\mathrm{pH}$ of solution decreases. The relations between the potentials of $C_{1}, C_{2}$ and $C_{3}$ and the $\mathrm{pH}$ of solutions are shown in Fig. 12. Linear relations as expressed by Eqs. (4) to (6) are obtained for $C_{1}, C_{2}$ and $C_{3}$ when the $\mathrm{pH}$ is lower than 4.0.

$$
\begin{array}{ll}
C_{1}: & E=0.727-0.058 \mathrm{pH}, \\
C_{2}: & E=1.377-0.137 \mathrm{pH}, \\
C_{3}: & E=1.531-0.098 \mathrm{pH} .
\end{array}
$$

The maximums of resistance corresponding to $R_{1}$ are observed in all the curves of Fig. 9 but the second maximums of resistance, which are designated $R_{2}$, exist in the potential region of secondary passivation only in the curves for the solutions having $\mathrm{pH}$ values lower than 2.6. The relations between the potentials of $R_{1}$ and $R_{2}$ and the $\mathrm{pH}$ of solutions are shown in Fig. 13 and the following linear relation is obtained for $R_{1}$.

$$
R_{1}: \quad E=0.875-0.048 \mathrm{pH} \text {. }
$$

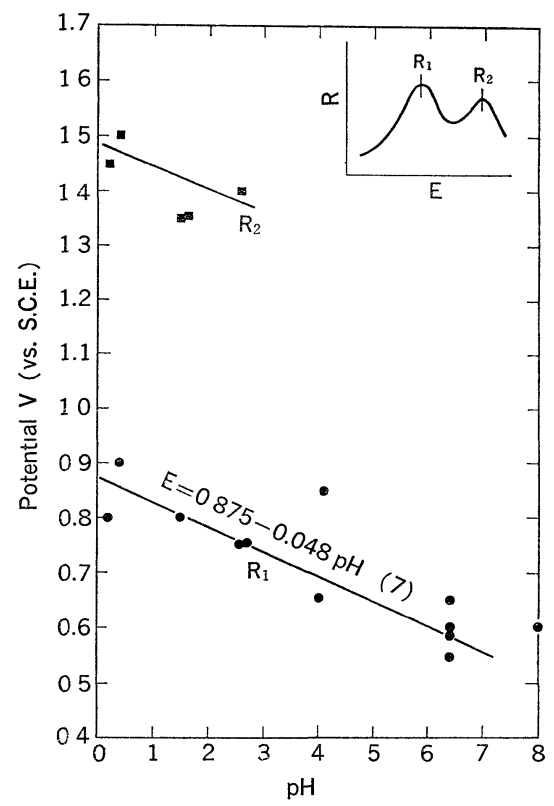

Fig. 13. Relations between the $\mathrm{pH}$ of solutions and the potentials of $R_{1}$ and $R_{2}$ for Type 304 stainless steel.

\section{Discussion}

4.1 Electrode reactions which are responsible for the characteristic changes in the $C-E$ and $\boldsymbol{R}-\boldsymbol{E}$ curves

The experimental results obtained for $C_{1}, C_{2}$ and $C_{3}$ in the $C-E$ curve and $R_{1}$ in the $R-E$ curve 
of Type 304 stainless steel are summarized as follows.

$C_{1}$ : (1) The minimum capacitances which correspond to $C_{1}$ are observed in metals and alloys, such as pure chromium, $\mathrm{Fe}-\mathrm{Cr}$ alloys $(20-70 \% \mathrm{Cr}$ ) and $\mathrm{Fe}-40 \% \mathrm{Ni}$ alloy, which exhibit a transition from the passive to the transpassive state. The potentials and capacitances of $C_{(\mathrm{Fe}-\mathrm{Cr}) 1}$ and $C_{(\mathrm{Fe}-\mathrm{Ni}) 1}$ are nearly equal to those of $C_{1}$. (2) The $\mathrm{pH}$ dependence of the potential of $C_{1}$ is in approximate agreement with that of the transpassive potential $E_{1}$; that is, the slopes of the straight lines $C$-pH (Fig. 12) and $E-$ pH (Fig. 11) give nearly equal values.

$C_{2}$ : (1) The maximum capacitances which correspond to $\mathrm{C}_{2}$ are observed in alloys, such as $\mathrm{Fe}-\mathrm{Cr}$ alloys containing 20 to $40 \%$ chromium, which show secondary passivation after transpassive dissolution. (2) The $\mathrm{pH}$ dependence of the potential of $C_{2}$ agrees fairly well with that of the secondary passivation potential $E_{2}$.

$C_{3}$ : (1) The minimum capacitances which correspond to $C_{3}$ are observed in metals and alloys, such as pure nickel and $\mathrm{Fe}-\mathrm{Cr}$ alloys containing 20 to $40 \%$ chromium, which show the oxygen evolution reaction after the secondary passivation. (2) The $\mathrm{pH}$ dependence of the potential of $C_{3}$ agrees fairly well with that of the oxygen evolution potential $E_{3}$.

$R_{1}$ : (1) The maximum resistances which correspond to $R_{1}$ are observed in metals and alloys which show the minimum capacitance corresponding to $C_{1}$ in the $C-E$ curve and the transition from the passive to the transpassive state in the anodic polarization curve. The potentials of $R_{(\mathrm{Fe}-\mathrm{Cr}) 1}$ and $R_{(\mathrm{Fe}-\mathrm{Ni}) 1}$ are nearly equal to that of $R_{1}$. (2) The $\mathrm{pH}$ dependence of the potential of $R_{1}$ agrees fairly well with that of $C_{1}$.

Consequently, $C_{1}$ and $R_{1}$ are related to the changes caused by the same origin, which is assumed to be the start of a transpassivation reaction. Since it can be considered that both $C_{1}$ and $R_{1}$ are influenced by the transpassivation reaction of chromium and/or nickel in Type 304 stainless steel, some electrode reaction presumed for the transpassivation and their equilibrium potentials, which have similar potentials and coefficients of pH terms to those in Eq. (4), are given by Eqs. (8) to (13). The values of standard free energy of formation used here are employed from the works of Latimer ${ }^{71}$ and Pourbaix. ${ }^{81}$

$$
\begin{aligned}
& \mathrm{Cr}_{2} \mathrm{O}_{3}+3 \mathrm{H}_{2} \mathrm{O}=2 \mathrm{CrO}_{3}+6 \mathrm{H}^{+}+6 \mathrm{e}^{-}: \\
& E=1.0451-0.0592 \mathrm{pH}+0.0197 \log a_{\mathrm{CrO}_{3}-\mathrm{ox}}
\end{aligned}
$$

$\mathrm{Cr}(\mathrm{OH})_{3}=\mathrm{CrO}_{3}+3 \mathrm{H}^{+}+3 \mathrm{e}^{-}:$

$E=1.1197-0.0592 \mathrm{pH}+0.0197 \log a_{\mathrm{CrO}_{3} \text {-OX }}$

hydrous $\mathrm{Cr}(\mathrm{OH})_{3}=\mathrm{CrO}_{3}+3 \mathrm{H}^{+}+3 \mathrm{e}^{-}$:

$E=0.9781-0.0592 \mathrm{pH}+0.0197 \log a_{\mathrm{CrO}_{3}-\mathrm{OX}}$

$\mathrm{CrOOH}+\mathrm{H}_{2} \mathrm{O}=\mathrm{CrO}_{3}+3 \mathrm{H}^{+}+3 \mathrm{e}^{-}$:

$E=1.1197-0.0592 \mathrm{pH}+0.0197 \log a_{\mathrm{CrO}_{3}-\mathrm{Ox}}$

$2 \mathrm{NiO}+\mathrm{H}_{2} \mathrm{O}=\mathrm{Ni}_{2} \mathrm{O}_{3}+2 \mathrm{H}^{+}+2 \mathrm{e}^{-}:$

$E=0.7868-0.0592 \mathrm{pH}+0.0296 \log a_{\mathrm{Ni}_{2} \mathrm{O}_{3} \text { - ox }}$

$$
\begin{aligned}
& 2 \mathrm{Ni}_{3} \mathrm{O}_{4}+\mathrm{H}_{2} \mathrm{O}=3 \mathrm{Ni}_{2} \mathrm{O}_{3}+2 \mathrm{H}^{+}+2 \mathrm{e}^{-}: \\
& E=1.059-0.0592 \mathrm{pH}+0.0888 \log a_{\mathrm{Ni}_{2} \mathrm{O}_{3}-\mathrm{OX}}
\end{aligned}
$$

$a_{\mathrm{CrO}_{3} \text {-OX }}$ and $a_{\mathrm{Ni}_{2} \mathrm{O}_{3} \text {-ox }}$ in those equations represent the activities of $\mathrm{CrO}_{3}$ and $\mathrm{Ni}_{2} \mathrm{O}_{3}$ in the passive film, respectively. Although a detailed knowledge of the chemical composition and structure of the passive and transpassive films is essential to determine the most reasonable reaction for the transpassivation of Type 304 stainless steel, the transpassivation of the steel seems to result from oxidation of a lower oxide containing species of $\mathrm{Cr}^{3+}$ and $\mathrm{Ni}^{2+}$, such as $\mathrm{Fe}_{2} \mathrm{O}_{3} \cdot \mathrm{Cr}_{2} \mathrm{O}_{3} \cdot \mathrm{NiO}$, to a higher oxide containing species of $\mathrm{Cr}^{6+}$ and $\mathrm{Ni}^{3+}$, such as $\mathrm{Fe}_{2} \mathrm{O}_{3} \cdot \mathrm{CrO}_{3} \cdot \mathrm{Ni}_{2} \mathrm{O}_{3}$.

The transpassive dissolution of Type 304 stainless steel seems to arise from the chemical dissolution of $\mathrm{CrO}_{3}$ formed in the passive film into aqueous solutions as follows:

$$
2 \mathrm{CrO}_{3} \cdot \mathrm{ox}+\mathrm{H}_{2} \mathrm{O} \rightarrow \mathrm{Cr}_{2} \mathrm{O}_{7}^{2-} \cdot \mathrm{aq}+2 \mathrm{H}^{+} .
$$

The same dissolution mechanism for transpassivity is also thought for pure chromium ${ }^{9,101}$ and binary $\mathrm{Fe}-\mathrm{Cr}$ alloys. ${ }^{11)}$

The activities of $\mathrm{CrO}_{3}$ in oxide films, $a_{\mathrm{CrO}_{3} \text {-ox }}$, at the potentials of $E_{1}$ or $C_{1}$ can be calculated by solving the simultaneous equations of Eq. (1) and one of Eqs. (8)-(11) or Eq. (4) and one of Eqs. (8)-(11), respectively. Calculated values of $a_{\mathrm{CrO}_{3} .0 \mathrm{X}}$ at the potentials of $E_{1}$ and $C_{1}$ for a solution of $\mathrm{pH} 0$ are listed in Table 2, where the potential of $E_{1}$ is more noble than, that of $C_{1}$.

Table 2. Calculated values of $a_{\mathrm{CrO}_{3} \text {-ox. }}$.

\begin{tabular}{ccc}
\hline $\begin{array}{c}\text { Equations } \\
\text { of the } \\
\text { reaction }\end{array}$ & $\begin{array}{c}a_{\mathrm{CrO}_{3}-\mathrm{Ox}} \\
\text { at the } \\
\text { potential of } C_{1}\end{array}$ & $\begin{array}{c}a_{\mathrm{CrO} 3-\mathrm{Ox}} \\
\text { at the } \\
\text { potential of } E_{1}\end{array}$ \\
\hline Eq. (8) & $10^{-16}$ & $10^{-7}$ \\
Eq. (9) & $10^{-20}$ & $10^{-11}$ \\
Eq. (10) & $10^{-13}$ & $10^{-4}$ \\
Eq. (11) & $10^{-20}$ & $10^{-11}$ \\
\hline
\end{tabular}


Table 2 shows that the activity of $\mathrm{CrO}_{3}$ in the passive film is so small at the potential of $C_{1}$ that the beginning of chemical reaction according to Eq. (14) can hardly be recognized by polarization measurements. However, according to the calculations from Eq. (8) or Eq. (10), the activity of $\mathrm{CrO}_{3}$ at the potential $E_{1}$ is large enough to distinguish the initiation of transpassive dissolution on the basis of the increase of current in the anodic polarization curve.

The change in capacitance at $C_{2}$ may be related to the secondary passivation of Type 304 stainless steel. Although the potential and capacitance of $C_{2}$ depend on the $\mathrm{pH}$ of the solutions, the electrochemical reactions of which equilibrium potentials have the same $\mathrm{pH}$ dependence as that of Eq. (5) cannot be found in the possible chemical reactions in which chromium compounds participate. Therefore, the secondary passivation of Type 304 stainless steel can be related not to a specific electrode reaction but to the increase of anodic polarization resulting from the decrease in chromium content and the enrichment of iron and nickel on the electrode surface with progress of the transpassive dissolution.

The minimum capacitance which corresponds to $C_{3}$ is assumed to be related to the oxygen evolution reaction because the $\mathrm{pH}$ dependence of the potential of $C_{3}$ agrees well with that of $E_{3}$.

\subsection{Relations between the variations in the oxide film and in the interfacial impedance}

As mentioned already, there are differences in the characteristic potentials between the $C-E$ curve and the anodic polarization curve. For example, by comparing Eq. (1) with Eq. (4) at an equal $\mathrm{pH}$, the potential of $C_{1}$ in the $C-E$ curve is less noble by about $170 \mathrm{mV}$ than the transpassive potential $E_{1}$ on the anodic polarization curve. Although the participation of Faradaic components in the impedance should be taken into account when the dissolution current of transpassivation is large, ${ }^{4)}$ Faradaic components may be neglected up to the potential $\mathrm{E}_{1}$ because the anodic polarization curves in this region show extremely small current densities corresponding to the passivity of Type 304 stainless steel.

Therefore, it is assumed that some changes related to the transpassivation may occur in the passive film even at the potential of $C_{1}$ which is more negative by about $170 \mathrm{mV}$ than the initial potential of the transpassive dissolution, $E_{1}$. With regard to the cause of these changes, the variations in thickness, composition or structure of the surface film may be considered. As for the variations in film thickness, it is difficult to attribute the increase of capacitance at a potential more positive than $C_{1}$ to the decrease in thickness of the surface film, since a continuous growth in thickness of the surface film at a potential more negative than the oxygen evolution potential has been shown by ellipsometric measurements ${ }^{3,12,14}$ and coulometric measurements. ${ }^{11,13)}$ Although the film is considered to be porous at a potential more noble than $E_{1}$ by the transpassive dissolution, ${ }^{1,2)}$ it can hardly be expected that there is a remarkable change in the structure of the film, such as the formation of a porous solid structure, at a potential between $C_{1}$ and $E_{1}$, because the dissolution current is very small below the potential $E_{1}$. Consequently, the variation in the dielectric constant of the film with film composition should cause the increase of capacitance above the potential $C_{1}$. According to the variation in film composition based on the mechanism of transpassivation stated before, it may be assumed that the amounts of $\mathrm{Cr}^{3+}$ and $\mathrm{Ni}^{2+}$ species decrease, and, on the contrary, those of $\mathrm{Cr}^{6+}$ and $\mathrm{Ni}^{3+}$ species increase in the surface film with increasing potential in the range more positive than the potential of $C_{1}$. The possibility of formation of a mixed oxide such as $\mathrm{Cr}_{2} \mathrm{O}_{3} / \mathrm{CrO}_{3}$ has been discussed by Vetter et al..$^{91}$ for a pure chromium electrode in the transpassive region.

\section{Conclusions}

The following conclusions were obtained by measuring interfacial impedances of Type 304 stainless steel under anodic polarization in the solution of $1 \mathrm{M}-\mathrm{Na}_{2} \mathrm{SO}_{4}$.

The capacitive component-potential curve ( $C-E$ curve) obtained in the solution at $\mathrm{pH} 6.4$ shows two minimums $C_{1}$ and $C_{3}$ at +0.40 and $+0.95 \mathrm{~V}$ (vs. SCE), respectively, and one maximum $C_{2}$ at $+0.75 \mathrm{~V}$. The resistive component-potential curve ( $R-E$ curve) has a maximum $R_{1}$ at $+0.60 \mathrm{~V}$ only. The minimums in capacitance corresponding to $C_{1}$ are also recognized in the $C-E$ curves for pure metal and binary alloys which exhibit the transition from passivation to transpassivation in the anodic polarization curves. The maximums in capacitance corresponding to $C_{2}$ are seen only for the alloys which show the transition from transpassivation to secondary passivation. The minimums in capacitance corresponding to $C_{3}$ are observed in the $C-E$ curves for pure metals and alloys which exhibit oxygen evolution reactions. 
The potentials at which $C_{1}, C_{2}$ and $C_{3}$ appear in the $C-E$ curve are dependent on the $\mathrm{pH}$ of the solutions and the $\mathrm{pH}$ dependence agrees fairly wel ${ }^{1}$ with that of the potentials at which the variation in current is observed in the anodic polarization curve. Accordingly, it may be concluded that the changes in capacitance which correspond to $C_{1}, C_{2}$ and $C_{3}$ are related to the electrode reactions of transpassivation, secondary passivation and oxygen evolution, respectively.

As the potential $C_{1}$ is always more negative by about $170 \mathrm{mV}$ than the initial potential of transpassive dissolution in the polarization curve, it is presumed that the variation in chemical composition of the passive film arising from the transpassive reaction begins at a lower potential than the potential at which an increase of current caused by the transpassive dissolution is observed.

(Received September 5, 1973)

\section{References}

1) M. Pražák, V. Pražák \& V. L. Číhal: $Z$. Elektrochem., 62, 739 (1958).
2) K. Shiobara, Y. Sawada \& S. Morioka: J. Japan Inst. Metals, 33, 239 (1969).

3) G. Okamoto \& T. Shibata: Corros. Sci., 10, 371 (1970).

4) K. Sugimoto \& Y. Sawada: Boshoku Gijutsu, 20, 264 (1971).

5) K. Sugimoto, Y. Sawada \& S. Morioka: J. Japan Inst. Metals, 33, 1042 (1969).

6) K. Sugimoto, Y. Sawada \& S. Morioka: Trans. Japan Inst. Metals, 12, 23 (1971).

7) W. M. Latimer: Oxidation Potentials (2nd Ed.), Prentice-Hall, New York (1952).

8) M. Pourbaix: Atlas of Electrochemical Equilibria in Aqueous Solutions, p. 330, Pergamon Press, London (1966).

9) W. J. Plieth \& K. J. Vetter: Z. Elektrochem. Ber. Bunsenges. Physik. Chem., 73, 1077 (1969).

10) H. Weidinger \& E. Lange: Z. Elektrochem., 64, 468 (1960).

11) M. Okuyama, S. Haruyama \& K. Nagasaki: Denki Kagaku, 37, 862 (1969).

12) V. V. Andreeva: Corrosion, 20, 35t (1964).

13) G. Aronowitz \& N. Hackerman: J. Electrochem. Soc., 110, 633 (1963).

14) K. N. Goswami \& R.W. Staehle: Electrochim. Acta, 16, 1895 (1971). 